\title{
Endoscopes that Complete Pre-Cleaning may be Stored Overnight until Next Morning for the Subsequent Reprocessing
}

\author{
Soo-Jeong Cho \\ Department of Internal Medicine and Liver Research Institute, Seoul National University Hospital, Seoul National University College of \\ Medicine, Seoul, Korea
}

See "Does the Reprocessing of Endoscopes Have to Take Place Immediately after Pre-Cleaning? A First Evaluation” by Vanessa M Eichel, Jonas M Jabs, Samy Unser, Nico T Mutters, Martin Scherrer, on page 526-533.

Professional reprocessing of flexible endoscopes is essential to prevent infection and for patient safety. Recently, the reprocessing process of endoscopes has been emphasized because of multiple outbreaks of multidrug-resistant organisms caused by inadequately reprocessed endoscopes. ${ }^{1-3}$ The reprocessing procedure comprises six stages: pre-cleaning, cleaning, disinfection, rinsing, drying, and storage. In the case of flexible endoscopes, a pre-cleaning or bedside cleaning process must be conducted immediately after use to remove coarse contaminants such as blood and tissue. The time interval of interim storage is not specified in most guidelines on endoscope reprocessing, including guidelines in the Republic of Korea, ${ }^{4,5}$ or they propose short periods between $30 \mathrm{~min}$ and $3 \mathrm{~h}^{6-9}$ Empirical studies on the effects of postponement on the reprocessing quality are not available. Due to these vague time frames, endoscope reprocessing can be troublesome after performing urgent endoscopy during weekends or night shifts. The study by Eichel et al. ${ }^{10}$ aimed to investigate the influence of postpon-

\footnotetext{
Received: April 24, 2021 Revised: May 25, 2021

Accepted: May 25, 2021

Correspondence: Soo-Jeong Cho

Division of Gastroenterology, Department of Internal Medicine and Liver Research Institute, Seoul National University Hospital, 101 Daehak-ro, Jongno-gu, Seoul 03080, Korea

Tel: 82-2-2072-4073, Fax: 82-2-762-9662, E-mail: crystal522@daum.net ORCID: https://orcid.org/0000-0001-7144-0589
}

(c) This is an Open Access article distributed under the terms of the Creative Commons Attribution Non-Commercial License (http://creativecommons.org/ licenses/by-nc/3.0) which permits unrestricted non-commercial use, distribution, and reproduction in any medium, provided the original work is properly cited. ing reprocessing on its quality after pre-cleaning of the flexible endoscopes. Residual protein content, germ load, and biofilm formation by photometry of crystal violet staining were tested, to evaluate performance efficacy of cleaning and disinfection, according to the time interval in the study. ${ }^{10}$ All test tubes and flexible endoscopes showed residual protein content and germ load significantly below the legally prescribed threshold values, independent of the interval between pre-cleaning and subsequent reprocessing process. In the study, biofilm was formed during storage after pre-cleaning, although it can be removed by brushing afterward. This study is the first to evaluate the effect of storage between pre-cleaning and subsequent reprocessing process. This study also suggested that endoscopes that complete pre-cleaning may be stored overnight until next morning for the rest of the reprocessing. However, to adopt this postponement strategy, thorough manual brushing should be ensured to remove biofilm that might have been formed during the storage without cleaning and disinfection. In addition, the number of repetitions is still too small to conclude sufficiency of the reprocessing quality, especially for storage time durations longer than $16 \mathrm{~h}$. Duodenoscopes that require critical reprocessing procedures were not included in this study. This study suggests that cleaning and disinfection may be delayed until next morning after pre-cleaning of contaminated endoscopes, especially in the emergency setting, which enables reduction of cost as well as human resources. However, further study is needed to apply this strategy in real clinical practice. 


\section{Conflicts of Interest}

The authors have no potential conflicts of interest.

Funding

None.

ORCID

Soo-Jeong Cho:

https://orcid.org/0000-0001-7144-0589

\section{REFERENCES}

1. Kumarage J, Khonyongwa K, Khan A, Desai N, Hoffman P, Taori SK. Transmission of multi-drug resistant Pseudomonas aeruginosa between two flexible ureteroscopes and an outbreak of urinary tract infection: the fragility of endoscope decontamination. J Hosp Infect 2019;102:89-94.

2. Naas T, Cuzon G, Babics A, et al. Endoscopy-associated transmission of carbapenem-resistant klebsiella pneumoniae producing KPC-2 beta-lactamase. J Antimicrob Chemother 2010;65:1305-1306.

3. Shimono N, Takuma T, Tsuchimochi N, et al. An outbreak of pseudomonas aeruginosa infections following thoracic surgeries occurring via the contamination of bronchoscopes and an automatic endoscope reprocessor. J Infect Chemother 2008;14:418-423.

4. Reprocessing Guideline Task Force, Petersen BT, Cohen J, et al. Multi-

society guideline on reprocessing flexible GI endoscopes: 2016 update. Gastrointest Endosc 2017;85:282-294.e1.

5. Cheung DY, Jang BI, Kim SW, et al. Multidisciplinary and multisociety practice guideline on reprocessing flexible gastrointestinal endoscopes and endoscopic accessories. Clin Endosc 2020;53:276-285.

6. Health Technical Memorandum 01-06: Decontamination of flexible endoscopes [Internet]. London: Department of Health \& Social Care UK; c2016 [cited 2021 May 31]. Available from: https://assets.publishing. service.gov.uk/government/uploads/system/uploads/attachment_data/ file/530418/HTM0106_PartA.pdf

7. 2020 Guidance on Decontamination of Equipment for Gastrointestinal Endoscopy [Internet]. London: The British Society of Gastroenterology; c2020 [cited 2021 May 31]. Available from: https://www.bsg.org.uk/ clinical-resource/guidance-on-decontamination-of-equipment-for-gastrointestinal-endoscopy/.

8. Infection control in Endoscopy [Internet]. Victoria: GESA; c2011 [cited 2021 May 31]. Available from: https://www.genca.org/public/5/files/ Endoscopy_infection_control\%20(low).pdf

9. Beilenhoff $\mathrm{U}$, Biering $\mathrm{H}$, Blum R, et al. Reprocessing of flexible endoscopes and endoscopic accessories used in gastrointestinal endoscopy: position statement of the European Society of Gastrointestinal Endoscopy (ESGE) and European Society of Gastroenterology Nurses and Associates (ESGENA) - update 2018. Endoscopy 2018;50:1205-1234.

10. Vanessa M Eichel, Jonas M Jabs, Samy Unser, Nico T Mutters, Martin Scherrer. Does the reprocessing of endoscopes have to take place immediately after pre-cleaning? a first evaluation. Clin Endosc 2021;54:526533. 